\title{
DE INVLOED VAN PRIJSREGELING EN RANTSOENEE- RING OP DE RENTABILITEIT VAN DEN DETAILHANDEL
}

\author{
door Dr. F. L. v. Muiswinkel
}

\section{INLEIDING.}

$\mathrm{Nu}$ de door de Overheid genomen maatregelen inzake rantsoeneering en prijsregeling geruimen tijd van kracht zijn, begint de invloed van deze maatregelen op de rentabiliteit der ondernemingen zich steeds scherper af te teekenen. Aanvankelijk werd het verkrijgen van een inzicht in de consequenties van deze overheidsinmenging, zoowel in het productie- als in het distributieproces, ten zeerste bemoeilijkt door de aanwezigheid van oude voorraden grondstoffen en producten. Door het liquideeren van deze voorraden behaalden vele ondernemingen namelijk zoo groote omzetten, dat de remmende invloed van de prijsregeling op de bruto en de netto winstmarges niet duidelijk aan het licht trad. Deze voorraadfactor heeft zijn beteekenis gedurende de laatste maanden evenwel grootendeels verloren, zoodat het thans zijn nut kan hebben om deze aangelegenheid nader te bezien.

Wij beperken ons daarbij tot de rentabiliteit van de ondernemingen in den detailhandel en zullen achtereenvolgens aandache besteden aan de volgende punten:

I. De inhoud van de prijsregeling,

II. Prijsregeling en bruto winstmarge,

III. Prijsregeling, rantsoeneering en netto winstmarge.

IV. Veranderingen in de samenstelling van den omzet,

V. De huidige rentabiliteit in den detailhandel, en

VI. Het beschermen van de toekomstige rentabiliteit.

\section{DE INHOUD VAN DE PRIJSREGELING.}

Vat men de tot dusver gegeven officieele voorschriften inzake de prijsvorming in den detailhandel in het kort samen, dan komt men al spoedig tot de ontdekking, dat de detaillist bij het vaststellen van de verkoopprijzen zijner artikelen tegenwoordig in een weinig benijdenswaardige positie verkeert. De detaillist moet zich namelijk houden aan de volgende richtlijnen:

A. Oude artikelen. Al naar gelang van de soort der artikelen moet hij kiezen tusschen

1. Den inkoopsprijs per 9 Mei 1940 plus den toenmaals geldenden opslag. (absoluut bedrag per eenheid)

2. Den toelaatbaren inkoopsprijs ${ }^{1}$ ) sedert 9 Mei 1940 plus den per dien datum geldenden opslag per artikel.

3. Den toelaatbaren inkoopsprijs plus een door den Gemachtigde voor de Prijzen vastgestelde percentueele marge.

4. De vastgestelde maximumprijzen voor den consument.

1) D.w.z. de inkoopsprijs per 9 Mei 1940 vermeerderd met de officieel gesanctioneerde verhoogingen.

$\mathrm{m}$ a b blz. 318 
B. Nieuwe artikelen. „De som van de werkelijk betaalde inkoopsprijs, voorzoover deze niet hooger is dan de toelaatbare, en de absolute bedragen voor algemeene kosten en winst, welke de handelaar bij vergelijkbare transacties in het eerste kwartaal van 1940 in het algemeen berekende of welke in die periode bij dergelijke transacties als gebruikelijk kunnen worden beschouwd."

C. Voorts moet de detaillist zich bij zijn prijszetting aan onderstaande, voor alle artikelen geldende voorschriften houden:

a. De prijs moet beantwoorden aan de eischen, welke het algemeen belang, in het bijzonder met betrekking tot de oorlogsomstandigheden, stelt.

b. Prijzen, welke hooger zijn dan de volgens a. geoorloofde, moeten worden verlaagd, ook dan, wanneer $z \mathrm{ij}$ volgens andere prijsvoorschriften geoorloofd zijn.

c. Indien tengevolge van vermeerdering van den omzet de kosten verminderd zijn en dientengevolge de netto winst per eenheid product ten opzichte van 9 Mei 1940 is gestegen, moet de prijs dienovereenkomstig worden verlaagd.

Zooals wij reeds opmerkten kan de posttie, waarin de detaillist thans bij zijn prijscalculatie verkeert, niet benijdenswaardig genoemd worden. De onder A (1, 2, 3 en 4) genoemde richtlijnen zijn nog het gemakkelijkst te hanteeren. Men bedenke daarbij echter, dat men in één en dezelfde branche met alle 4 richtlijnen te maken kan hebben.

Een voorbeeld daarvan vindt men in den groentenhandel. Voor sommige conserven gelden de richtlijnen $A 1$ en A 2. Voor de versche groenten moet een calculatie gemaakt worden, waarbij de toelaatbare inkoopsprijs met $30 \%$ mag worden verhoogd (A 3). Voor sommige artikelen (asperges b.v.) gelden daarentegen weer maximumprijzen (A 4). Bovendien publiceert de Gemachtigde voor de Prijzen sedert eenigen tijd in de pers series prijzen voor de afzonderlijke artikelen, welke ten hoogste aan den consument in rekening gebracht mogen worden; bedoelde prijzen zijn echter naar uitdrukkelijk wordt vermeld, geen officiëele maximumprijzen.

Ten aanzien van de onlangs afgekondigde algemeene richtlijnen (zie C) is het voor den individueelen handelaar echter nog minder eenvoudig om tot een calculatie te komen, waarvan hij bij voorbaat overtuigd kan zijn, dat de Gemachtigde voor de Prijzen daarmede accoord gaat. Naar aanleiding van deze richtlijnen, welke neergelegd zijn in het Prijsvormingsbesluit 1941 en de daarbij behoorende Uitvoeringsbeschikking, kunnen b.v. de volgende vragen gesteld worden:

1. Hoe kan de individueele detailhandelaar zijn verkoopprijzen toetsen aan de eischen, welke het algemeen belang stelt?

2. Welke marge is nu eigenlijk geoorloofd voor nieuwe artikelen? De opslag voor algemeene kosten en winst moet weliswaar overeenstemmen met die van vergelijkbare transacties in het eerste kwartaal 1940, doch volgens art. 2 sub 4 van het besluit moeten , als nieuwe goederen worden beschouwd alle goederen, welke van de op 9 Mei 1940 in het verkeer zijnde goederen in zoo belangrijke mate afwijken, dat zij daarmede niet of niet meer kunnen worden vergeleken" 2 )

2) Cursiveering van ons.

m a b blz. 319 
3. Moet elke stijging van den omzet, die tot een vermindering van de kosten per eenheid leidt, onmiddellijk in een verlaging van de verkoopprijzen tot uitdrukking worden gebracht? Zoo ja, welke eischen moeten dientengevolge worden gesteld aan het rekeningsysteem in den detailhandel? Zoo neen, van welke duur en welke afmeting moet de omzetstijging zijn, alvorens men tot een verlaging der verkoopprijzen verplicht is?

\section{PRIJSREGELING EN BRUTO WINSTMARGE}

Onder normale omstandigheden pleegt men in den detailhandel bij de calculatie veelal uit te gaan van een percentueelen opslag op den inkoopsprijs der goederen. Het grondbeginsel van de huidige officiëele prijsregeling bestaat echter in het verhoogen van den toelaatbaren inkoopsprijs met een vast geldbedrag per eenheid; op dit grondbeginsel bestaan enkele uitzonderingen, zooals in den groentenhandel.

$\mathrm{B}_{\mathrm{ij}}$ het ontbreken van eenheid in de in het voorafgaande geschetste richtlijnen voor de huidige prijsregeling wordt de bruto winstmarge in den detailhandel thans echter op zeer verschillende wijze beinvloed, en wel als volgt:

\begin{tabular}{|c|c|c|}
\hline Wijze van prijsbepaling & $\begin{array}{l}\text { Absoluut bedrag } \\
\text { per eenheid }\end{array}$ & $\begin{array}{l}\text { Percentueele } \\
\text { marge }\end{array}$ \\
\hline 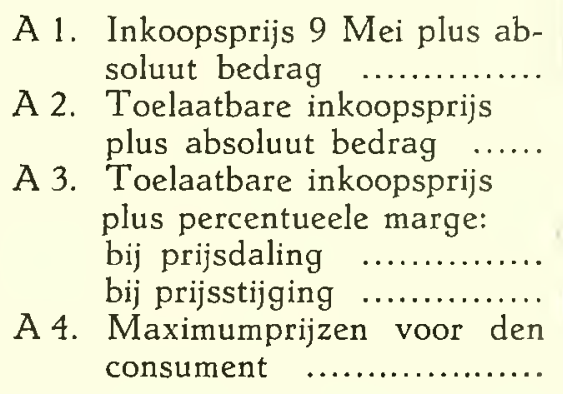 & $\begin{array}{l}\text { onveranderd } \\
\text { onveranderd } \\
\text { gedaald } \\
\text { gestegen } \\
\text { onzeker }\end{array}$ & $\begin{array}{c}\text { onveranderd } \\
\text { onveranderd } \\
\text { onzeker }\end{array}$ \\
\hline
\end{tabular}

Bovendien moet bij een stijging van den omzet, welke een vermindering van de bedrijfskosten per eenheid verhandeld product veroorzaakt, de opslag op den inkoopsprijs worden verlaagd, zoodat uit dezen hoofde de tendenz tot een verlaging van de percentueele marge over de geheele linie zal optreden.

Opgemerkt moge in dit verband nog worden, dat de verplichte prijsverlaging op grond van gestegen omzet geldt voor den individueelen detailhandelaar; voor één en hetzelfde product zullen verschillende detailhandelaren dus verschillende verkoopprijzen moeten berekenen, al naar gelang van de omstandigheid of de omzet in de desbetreffende zaken al dan niet gestegen is. Tot welke consequenties een en ander o.m. zal voeren ten aanzien van de verplichte prijshandhaving van merkartikelen mag met belangstelling worden afgewacht. 
Bij het nagaan van den invloed, welke prijsregeling en rantsoeneering hebben op de netto winstmarge ontmoet men als vanzelf het vraagstuk van de bedrijfskosten. Dr. Winsemius, Hoofd van de afdeeling Prijsvorming, betoogde in dit verband, in een door hem aan het Utrechtsch Nieuwsblad verleend interview, het volgende:

"Een deftige winkel in het Noordeinde te Den Haag, met een geperfectioneerde "service" voor zijn klanten, zal noodzakelijkerwijze een hoogere kostenstructuur hebben dan zijn collega in een volkswijk, welke laatste op zijn beurt weer een hoogere kostenstructuur heeft dan zijn collega op het platteland. Legt men nu de prijzen vast op het laagste niveau, dan wordt de winkelier met de hoogere onkosten doodgedrukt, terwiil bij een prijsfixeering op het hoogste niveau een groot deel van de bevolking - en juist het minst kapitaalkrachtige - te veel zou moeten betalen. Een indeeling van de winkeliers in verschillende groepen voor al de vele branches, welke er zijn, acht men in de praktijk niet wel mogelijk."

Blijkens bovenstaande opmerkingen kan er bij de huidige prijsregeling geen rekening worden gehouden met de bedrijfskosten van den individueelen detailhandelaar, terwijl er evenmin gelet wordt op de draagkracht van de desbetreffende bedrijven.

$\mathrm{Bij}$ de detailhandelsondernemingen moet het geheel van de eigenlijke bedrijfskosten (loonen, huur, verlichting, telefoon, bezorgingskosten, afschrijving enz.) bestreden worden uit de bij de prijsregeling vastgelegde marge boven den inkoopsprijs der goederen. De netto winstmarge is dientengevolge bij de detailhandelsondernemingen op een zeer onzekere basis geconstrueerd, temeer waar de bruto winstmarge, zooals wij in het voorafgaande zagen, in vele gevallen eveneens wankel is. ${ }^{3}$ )

In het bijzonder voor de detailhandelaren, die in het verleden door middel van ongemotiveerde prijsconcurrentie hun omzet trachtten te vergrooten, brengt de huidige situatie onprettige consequenties met zich mede. De bestaande prijsvoorschriften maken het voor hen onmogelijk om de door hen in het verleden aangelegde marge alsnog te verhoogen: de prijsknoeiers moeten blijven knoeien. Bovendien bestaat ook voor deze categorie detailhandelaren de verplichting om hun verkoopprijzen te verlagen, wanneer een stijging van den omzet tot een verhooging van de netto winst per eenheid product zou leiden.

Ook de ontwikkeling van de bedrijfskosten zelve verdient de aandacht. Een illustratie van deze ontwikkeling vindt men in de uitkomsten van een door het Economisch Instituut voor den Middenstand ingesteld onderzoek naar de rentabiliteit in den groentenhandel, welke ten aanzien van de bedrijfskosten het volgende beeld opleveren: (vergelijking van overeenkomstige perioden in de jaren 1940 en 1941 voor 17 gevallen)

Op goede gronden kan worden aangenomen. dat zich in alle takken van den detailhandel een soortgelijke ontwikkeling voltrekt. De prijzen van het verpakkingsmateriaal zijn sterk gestegen; de kosten van het bezorgen der goederen zijn eveneens toegenomen, vooral in die branches,

3) Voor het verschil in behandeling met de productie-ondernemingen, neme men kennis van ons artikel "De invloed van prijsregeling en rantsoeneering op den detailhandel", in Ec. Statistische Berichten van 4 Juni 1941.

$\mathrm{m}$ a b blz. 321 


\begin{tabular}{|c|c|c|c|c|}
\hline & & 1940 & & 941 \\
\hline $\begin{array}{l}\text { Totale bedrijfskosten (zonder gewaardeerd } \\
\text { loon) } \quad \ldots \ldots \ldots \ldots \ldots \ldots \ldots \ldots \ldots \ldots \ldots \ldots \ldots \ldots \ldots \ldots \\
\text { waarvan: }\end{array}$ & $f$ & 18.115 & $f$ & 19.815 \\
\hline $\begin{array}{l}\text { Betaalde loonen } \ldots \ldots \ldots \ldots \ldots \ldots \ldots \ldots \ldots \ldots \ldots \ldots \\
\text { Onderhoud vervoermiddelen } \quad \ldots \ldots \ldots \ldots \ldots \ldots \ldots \\
\text { Verpakkingsmateriaal } \quad \ldots \ldots \ldots \ldots \ldots \ldots \ldots \ldots\end{array}$ & $\begin{array}{l}\text { " } \\
\text { ", }\end{array}$ & $\begin{array}{l}5.043 \\
1.272 \\
1.082\end{array}$ & $\begin{array}{l}", \\
", \\
\text { ", }\end{array}$ & $\begin{array}{l}5.684 \\
1.665 \\
1.567\end{array}$ \\
\hline
\end{tabular}

waar de autotractie moest worden vervangen door paard en wagen. De tendenz tot het stijgen van de betaalde loonen houdt eenerzijds verband met de meerdere tijdroovendheid van de bezorging, en anderzijds met de toeneming van de administratieve werkzaamheden ingevolge de distributie (men denke hierbij b.v. aan de bonnenadministratie).

Onder overigens gelijkblijvende omstandigheden hebben prijsregeling en rantsoeneering derhalve de tendenz om de netto winstmarge per eenheid verhandeld product te verkleinen. Bij de behandeling van ,De Huidige rentabiliteit in den Detailhandel" (V) komen wij op deze kwestie nader terug.

\section{VERANDERINGEN IN DE SAMENSTELLING VAN DEN OMZET}

Prijsregeling en rantsoeneering oefenen een invloed uit op de samenstelling van den omzet in den detailhandel, welke de rentabiliteit der betrokken bedrijven op den duur niet onberoerd kan laten.

Wat de prijsregeling betreft zij er b.v. op gewezen, dat zoowel de producenten als de detailhandelaren weinig interesse meer overhouden voor de kwaliteit der voortgebrachte of verhandelde producten. De prijsregeling houdt zich namelijk wèl bezig met de soorten artikelen, doch laat nagenoeg geen ruimte over voor een extra-vergoeding op grond van kwaliteitsproductie of zorgvuldige selectie. Tengevolge van de heerschende schaarschte brengt iedere kwaliteit van een goed al te gemakkelijk den maximum toelaatbaren prijs op. Afnemende interesse voor kwaliteitsproducten bij producent en handelaar leidt automatisch tot verslechtering van de kwaliteit. In het bijzonder geldt zulks voor de producten van agrarischen oorsprong.

$\mathrm{Bij}$ de industrieele productie treedt voorts het verschijnsel op den voorgrond, dat men onder den invloed van de voorgeschreven calculatieschema's meer belangstelling gaat koesteren voor de dure soorten artikelen, omdat de productie van de dure soorten meer profijt oplevert.

Ook van dit verschijnsel kan men de gevolgen terugvinden in de optredende verschuivingen in de samenstelling der winkeliers-assortimenten.

$$
*
$$

De consequenties van prijsregeling en rantsoeneering ten aanzien van de samenstelling van den omzet en van de bruto winst blijken o.m. uit een door het Economisch Instituut voor den Middenstand ingesteld onderzoek naar de huidige rentabiliteit van het kruideniersbedrijf.

m a b blz. 322 
Ten behoeve van dit onderzoek werden bij een 20-tal kruidenierszaken alle inkoopfacturen over de maanden Januari 1940 en Januari 1941 stuk voor stuk doorgenomen, en werden de desbetreffende artikelen (meer dan 1000) in 29 groepen gerangschikt. Vervolgens werd de inkoopsprijs en de verkoopprijs van elk artikel afzonderlijk vastgesteld, teneinde de verkoopwaarde van den inkoop en de theoretische bruto winst te kunnen bepalen. Voor elke groep artikelen zijn vervolgens onderstaande gegevens berekend:

a. Verkoopwaarde van den inkoop. (in guldens en in \% van de totale verkoopwaarde)

b. Theoretische bruto winst (in guldens en in \%o van de verkoopwaarde)

c. Bruto winst in \% van de totale theoretische bruto winst.

Bedoelde gegevens vindt men in den staat op blz. 324 .

De invloed van de rantsoeneeringsmaatregelen en van de schaarschte aan sommige groepen artikelen vindt men in dezen staat duidelijk weerspiegeld. Men neme daartoe kennis van de percentages in de kolommen 2 en 7 en vergelijke de desbetreffende gegevens per groep artikelen. De verschuivingen in de samenstelling van den inkoop (omzet) blijken zeer sterk te zijn.

Zoo daalde het aandeel van groep 5 (Koffie en thee) in den totalen inkoop (verkoop) van $6.37 \%$ in Januari 1940 tot $2.05 \%$ in Januari 1941. Het aandeel van de groep Surrogaten (6) is gestegen van $0.08 \%$ tot $1.40 \%$.

Grutterswaren (groep 3) namen toe van $3.37 \%$ tot $6.60 \%$. De groepen 13 (biscuits), 15 (zuidvruchten), 20 (vleeschwaren), 2 (jam, stroop), 25 (soepen) en 28 (wijn, bier en limonade) geven al even opvallende veranderingen te zien.

Deze verschuivingen in de samenstelling van den omzet oefenen uiteraard tevens een merkbaren invloed uit op de samenstelling en de grootte van het totale bruto winstbedrag. De groep artikelen koffie en thee, die in Januari 1940 nog $6.29 \%$ van de totale bruto winst opleverde (zie kolom 5), vertegenwoordigde in Januari 1941 nog slechts $1.97 \%$ van de totale bruto winst (zie kolom 10). Bij andere groepen vindt men soortgelijke wijzigingen.

Zou men in andere branches van den detailhandel een analoog onderzoek instellen, dan zou men ook in deze branches ongetwijfeld dezelfde ontdekkingen doen. Bij de kruideniersbranche heffen voor- en achteruitgang van verschillende groepen elkaar nagenoeg op. Of zulks op den duur het geval zal zijn en of deze compensatie in alle branches aan den dag zal treden, mag betwijfeld worden.

Ook uit dezen hoofde moet men in den detailhandel derhalve op ingrijpende wijzigingen van de rentabiliteit bedacht zijn, temeer waar de bedrijfskosten in den detailhandel in overwegende mate een vast karakter dragen. ${ }^{4}$ )

4) Zie ons artikel „De Calculatie in den Detailhandel” in het April-nummer van M.A.B. 
De in het voorafgaande geschetste consequenties van prijsregeling en rantsoeneering hebben in de kringen van den detailhandel tot voor korten tijd weinig belangstelling genoten. De oorzaak daarvan moet gezocht worden in de omstandigheid, dat de geldomzetten in verschillende branches van den detailhandel zich sedert Mei 1940 op een niet onbelangrijk hooger peil bewogen dan voor dien tijd het geval was. Deze stijging van den omzet moet o.m. worden toegeschreven aan het uitverkoopen van (deels incourante) voorraden, de groote inkoopen van het publiek van niet-gerantsoeneerde artikelen, de verminderde spaarzin der consumenten en aan de vlucht in goederen van langeren levensduur.

Deze stijging van den omzet veroorzaakte in sommige branches een niet onbelangrijke verhooging van de bruto en van de netto winst. Men neme in dit verband b.v. kennis van de desbetreffende cijfers op blz. 324. De verkoopwaarde van den inkoop van bedoelde 20 kruideniers steeg van $f 52.273$ in Januari 1940 tot $f 61.437$ in Januari 1941, d.i. met $17.5 \%$. De theoretische bruto winst nam toe van $f 11.630$ tot $f 13.393$.

De bedrijfskosten namen weliswaar ook toe, doch in veel geringere mate dan de bruto winst.

Een en ander duidt op een aanvankelijke verhooging van de rentabiliteit.

Dat deze toestand zich in de toekomst op soortgelijke wijze zal blijven ontwikkelen moet ernstig betwijfeld worden. In de eerste plaats dient men zich immers het feit te realiseeren, dat de schaarschte aan grondstoffen en verhandelbare goederen hand over hand toeneemt. De daling van de hoeveelheidsomzetten zal zich in de toekomst derhalve sterker manifesteeren.

Bovendien moeten de detailhandelaren, sedert de publicatie van de „Eerste uitvoeringsbeschikking van het Prijsvormingsbesluit 1941", overgaan tot het verlagen van de verkoopprijzen, indien tengevolge van vermeerdering van den omzet de kosten verminderd zijn en dientengevolge de netto winst per eenheid product ten opzichte van 9 Mei 1940 is gestegen.

De voordeelen van de gestegen omzetten zullen bij naleving van de jongste bepalingen eveneens teniet gaan en dus zullen de consequenties van prijsregeling en rantsoeneering zich in de nabije toekomst in volle $z$ waarte openbaren.

In eenige takken van den detailhandel heeft de schaarschte de daling van den omzet trouwens reeds krachtig in de hand gewerkt. Men denke in dit verband b.v. aan de slagersbranche. In het jaar 1939 bedroeg het gemiddelde vleeschverbruik in Nederland $39,25 \mathrm{~kg}$. per hoofd der bevolking; bij de huidige rantsoenen kan dit verbruik, wanneer alle bonnen worden aangeboden, ten hoogste $14,5 \mathrm{~kg}$. zijn. Het zal geen nader betoog behoeven, dat de rentabiliteit van het slagersbedrijf onder deze omstandigheden ernstig moet zijn aangetast; of liever, dat de rentabiliteit van dit bedrijf thans praktisch verdwenen is.

Een soortgelijke ontwikkeling dreigt op het terrein van de schoenwinkeliers; de geringe toewijzing van bonnen drukte de geldomzet in deze bedrijven in het jongste verleden zeer sterk.

De banketbakkerij, die tot voor kort nog weinig hinder ondervond, dreigt door de onlangs gewijzigde brood- en meelrantsoenen eveneens te worden gedupeerd. 
Een en ander wijst er op, dat de aantasting van de rentabiliteit snelle vorderingen maakt.

\section{HET BESCHERMEN VAN DE TOEKOMSTIGE RENTABILITEIT}

Het van ouds bekende probleem van dalende omzetten en dalende bruto winst eenerzijds en vrijwel constante bedrijfskosten anderzijds, heeft door de prijsregeling en de rantsoeneering een nieuw accent gekregen. Een compensatie van dalende hoeveelheidsomzetten door verhooging van de bruto winstmarge is thans onmogelijk, hetgeen te pijnlijker aandoet, omdat een verhooging van den omzet wèl tot een verlaging van de marge per eenheid leiden moet. Naarmate de schaarschte aan goederen en grondstoffen zich sterker manifesteert zal de rentabiliteit van de ondernemingen in den detailhandel sterker worden aangetast.

Sterker dan ooit klemt momenteel dan ook de vraag hoe deze rentabiliteit zal kunnen worden beschermd.

Naar het ons voorkomt ligt hier zoowel een taak voor de overheid als voor den individueelen detailhandelaar.

Ten aanzien van de taak van de overheid kunnen wij in het bestek van dit artikel kort zijn. Nauwgezette prijshandhaving van goederen en diensten, welke de bedrijfskosten in den detailhandel bepalen, is uiteraard een eerste vereischte. Daarnaast ware het verloop van de rentabiliteit in den detailhandel op den voet te volgen, teneinde den detailhandelaar door herziening van de prijsvoorschriften zoo noodig meer armslag te geven. Ook het standpunt van de overheid ten aanzien van het vraagstuk van de onderbezetting zou naar het ons voorkomt aan een herziening onderworpen kunnen worden.

$\mathrm{Op}$ de ondernemers zelf zal echter het grootste gedeelte van de taak blijven rusten om de rentabiliteit der bedrijven in tact te houden. Zoowel voor de groot- als de kleinbedrijven in den detailhandel bestaan in dit opzicht nog verschillende mogelijkheden. Afgezien van het opvoeren der efficiency in het algemeen willen wij in het bijzonder op een tweetal punten de aandacht vestigen.

In de eerste plaats op de mogelijkheid tot vrijwillige concentratie van het aantal verkoopplaatsen. Door het samenvoegen van 2 of meer winkels (c.q. filialen) is in sommige gevallen ongetwijfeld een aanzienlijke kostenbesparing te bereiken. De tegenwerping, dat de goodwill van het verkoopapparaat dientengevolge voor een deel verloren gaat, snijdt in dezen tijd veelal geen hout meer. De bestaande schaarschte aan goederen drijft het publiek automatisch naar de winkels; de vraag is niet meer, word ik in die of die winkel volkomen naar mijn zin behandeld, doch de aanwezigheid der goederen is voor den consument op zichzelf reeds doorslaggevend. De beteekenis van de goodwill van het verkoopapparaat is door de schaarschte zoozeer afgenomen, dat zij, althans voor den verkoop van eerste levensbehoeften, praktisch verwarloosd kan worden.

Het tweede punt waarop wij in het voorafgaande doelden, is de contröle op het goederenbeheer in den detailhandel. Vooral bij de kleinbedrijven valt op dit punt nog zeer veel te verbeteren, getuigen onderstaande cijfers uit de Statistiek voor het Kruideniersbedrijf over het boekjaar $1939 / 1940$.

m a b blz. 326 
Vergelijking theoretische bruto winst Januari 1941 en Januari 1940 met de in werkelijkheid behaalde bruto winst.

\begin{tabular}{c|c|c|c}
\hline \multirow{2}{*}{ Geval No. } & \multicolumn{2}{|c|}{ Theoretische bruto winst } & \multirow{2}{*}{$\begin{array}{c}\text { Werkelijke bruto winst } \\
\text { boekjaar 1939/1940 }\end{array}$} \\
\cline { 2 - 4 } & Jan. 1941 & Jan. 1940 & 11.2 \\
\hline 33 & 24.0 & 24.4 & 17.0 \\
137 & 20.0 & 19.2 & 11.6 \\
177 & 17.7 & 16.1 & 11.5 \\
87 & 18.0 & 19.0 & 13.2 \\
72 & 20.0 & 20.1 & 18.4 \\
81 & 23.0 & 26.4 & 15.4 \\
244 & 20.8 & 22.6 & 10.5 \\
44 & 20.0 & 20.0 & 14.8 \\
13 & 18.9 & 23.0 & 12.7 \\
129 & 19.7 & 19.2 &
\end{tabular}

De theoretische bruto winst (d.i. het verschil tusschen den inkoopsprijs en den gecalculeerden verkoopprijs) kan in de praktiik weliswaar niet volkomen gelijk zijn aan de in werkelijkheid behaalde bruto winst, doch ver schillen als de bovenstaande zijn zoo groot, dat er in deze gevallen on miskenbaar van fouten in het goederenbeheer gesproken zal moeten worden. Het gaat hier niet om enkele procenten van den omzet, doch om bedragen, welke de gemiddelde netto winst van de detailhandelaren evenaren. Een scherpere controle op het goederenbeheer zal in vele gevallen uitkomst kunnen brengen, wanneer de rentabiliteit ook uit anderen hoofde wordt aangetast.

Mogen betrokkenen, ondanks de beslommeringen verbonden aan prijsregeling en distributievoorschriften, de gelegenheid vinden om aan deze aangelegenheid de aandacht te schenken, welke zij verdient.

\section{INSTRUCTIE VOOR DE ASSISTENTEN TEN AANZIEN VAN BALANSWERKZAAMHEDEN}

door L. G. van der Hoek

Uit het naschrift van den Heer $P . J . H . J$. Bos onder mijn artikel in het Maandblad van Juli blijkt, dat de Heer Bos in twee opzichten met mij van meening verschilt, n.l. over de beteekenis van de ,algemeene instructie" en over de taak van den ,eersten assistent".

Hierbij valt onmiddellijk op te merken, dat het schijnbare verschil van meening betreffende de door mij onder A genoemde werkzaamheden m.i. op een misverstand berust. Ik heb slechts een onderscheid willen maken tusschen de werkzaamheden, welke de Heer Bos in zijn eerste artikel heeft behandeld op een wijze, waarmede $i k$ mij in groote trekken heb kunnen vereenigen, en die waaraan hij m.i. te weinig aandacht heeft besteed. De summiere opsomming der eerstbedoelde werkzaamheden maakt niet in het minst aanspraak op volledigheid. Ik meen dus, dat wij het wat betreft de door mij onder A genoemde werkzaamheden wel eens zijn.

Wat nu de algemeene instructie betreft, acht de Heer Bos het niet

$\mathrm{m}$ a b blz. 327 